\title{
Child Sexual Abuse Workers' Emotional Experiences of Working Therapeutically in the Western Cape, South Africa
}

\author{
Charlotte Capri · Lou-Marie Kruger • \\ Mark Tomlinson
}

\begin{abstract}
South African child sexual abuse workers active in low-income communities bear witness to stories of sexual and physical abuse, neglect, pervasive deprivation, and violence. North American, British, and European workers' emotional experiences have been captured in the literature, and a gap remains to be filled by those of their South African colleagues. This research aims to focus on the emotional experiences of social workers who engage therapeutically with sexually abused children in the Helderberg basin of the Western Cape, and resonate in some way with readers working in situations of poverty and trauma in other parts of the world. This study employed an explorative inductive research method, and followed a critical realist and contextual constructionist approach. Multiple-case study data collection took place by means of semi-structured interviews with social workers who engage therapeutically with sexually abused children. Data were examined by means of thematic analysis, and psychoanalytic theory was employed to analyse defences that surfaced during interviews. There were similarities in emotional experiences between South African participants and their abovementioned counterparts. The research also identified salient features of working with child sexual abuse in South Africa. The emotional experiences of doing such work, coupled with participants' ways of managing sexually abused children's material, gave rise to
\end{abstract}

C. Capri (\&) · L.-M. Kruger · M. Tomlinson

Unit for Clinical Psychology and Community Counselling, Department of Psychology, University of Stellenbosch, GG Cillie Building, Ryneveld Street, Stellenbosch 7600, South Africa e-mail: charlottecapri@cybersmart.co.za

L.-M. Kruger

e-mail: lkrug@sun.ac.za

M. Tomlinson

e-mail: markt@sun.ac.za

C. Capri · L.-M. Kruger · M. Tomlinson

Department of Psychology, University of Stellenbosch, Private Bag X1, Matieland,

Stellenbosch 7602, South Africa 
possible vicarious traumatisation symptoms and allowed for a psychoanalytic understanding to be put forward. The research also reports on useful measures that might enable individuals to continue interventions. To enable ongoing effective therapeutic engagement, social workers should have access to opportunities for acknowledging countertransferences and processing dynamic material defended against. The research contributes to knowledge of working in South Africa by exploring the emotional experiences of those who help sexually abused children daily, and by investigating the psychological impact prolonged therapeutic engagement has on workers active in Western Cape low-income communities.

Keywords Child sexual abuse workers - Emotional experiences · Defences · Psychoanalytic theory · South Africa

\section{Introduction}

South African child sexual abuse workers active in low-income communities bear witness to stories of abuse and neglect, pervasive poverty, violence, hunger, and deprivation. Working therapeutically with sexually abused children is "exceptionally difficult" (Reynolds-Mejia and Levitan 1990, p. 61), and Ralph (2001) comments on "[s]urviving the abused child" (p. 288). Children may project their shock and outrage, leaving workers vulnerable to traumatogenic introjections (Brady et al. 1999; Collins and Long 2003; Didhama et al. 2011).

The emotional experiences of mostly North American, British, and European child sexual abuse workers have been captured in literature which seeks to understand such experiences in terms of vicarious traumatisation. These can also be appreciated by exploring defences employed to manage anxiety elicited by thoughts and feelings about child sexual abuse work, and the influence these may have on workers (Follette et al. 1994; Jenkins an Baird 2002; Mills 2012). In light of the lack of an equivalent South African literature, this research contributes to knowledge of engaging therapeutically with sexually abused children in South Africa by exploring the emotional experiences of their therapists and by investigating the psychological impact such work might have on them.

Child sexual abuse is any sexual activity with a child, under the country-specific age of legal consent, intended for the sexual gratification of an adult or substantially older child (Dawes et al. 2004; Potgieter 2000; Russell 1986). Contemporary conceptualisations cover a wide range of acts due to international differences in child protection laws and little consensus regarding definitions (Johnson 2004; Levett 2002; Swartz 2002).

A psychoanalytic understanding describes the sexual abuse of a child as the abuser...raping the child's mind... a piece of madness is forced into [the child] so that the child can no longer make sense of his experiences, thoughts and feelings. [T] he same process can happen to those working with the child (Ralph 2001, p. 286). 
Given this interpretation, such "madness" can be transferred into the therapist, resulting in internalised confusion, protectiveness, sadism, an inability to think (Ralph 2001); (over)identification with the child victim (Reynolds-Mejia and Levitan 1990); and feelings of inadequacy, frustration, helplessness, rage, and anger (McElroy and McElroy 1991; Shevade et al. 2011).

Projective identification suggests that good or bad parts of oneself are split off and located in another whilst a connection to this expulsion is maintained through unconscious identification (Klein 1932/1975; Mancillas 2006; Waska 2007). Splitoff parts of the child clients might be projected into their social workers so that they can also experience the intolerable conflict. In this way, engaging therapeutically with sexually abused children might leave therapists feeling like the childrenintruded upon, burdened, defeated, contaminated, and exploited (Cunningham 1999; Schauben and Frazier 1995). This implies that "[p]rojective identification is intimately involved in the phenomenon of countertransference" (Clarkson and Nuttall 2000, p. 362). In this study, the use of countertransference includes needs and unresolved conflicts, and encompasses all the feelings a therapist may experience when engaging with child sexual abuse material (Gabbard 2001; Rosenberger and Hayes 2002; Shevade et al. 2011). A perceived invasion of personal boundaries can intensify countertransference reactions, which may be defended against by disengaging from children's narratives. Such detachment could mirror the child's affectual state, but also present a potential treatment barrier since a therapeutically rich connection to the child's underlying emotion is lost (Reynolds-Mejia and Levitan 1990; Way et al. 2004).

It has been suggested that, after prolonged contact with such material, workers may start to experience the world, themselves, and others in a more cynical way (Brady et al. 1999; Jankoski 2010; Schneider 2003). In terms of Kleinian object relations theory, the stress of introjecting traumatogenic narratives can drive a worker to the paranoid-schizoid position. By means of a subsequent splitting defence a negative view of the world, others, and themselves could develop (Mitchell and Black 1995; Schneider 2003; St. Clair 1996).

The emotional experience of prolonged child sexual abuse work in low-income communities in the Western Cape, coupled with participants' ways of managing traumatogenic material, may give rise to possible vicarious traumatisation symptoms and allows for a psychoanalytic understanding to be put forward. This research contributes to knowledge of working with child sexual abuse in South Africa by exploring the emotional experiences of those who attempt to help, and by investigating the psychological impact thereof on social workers active in Western Cape low-income communities on a daily basis. It also aims to resonate in some way with readers working in situations of poverty and trauma in other parts of the world.

\section{Rationale}

The study approaches child sexual abuse work from a psychoanalytic perspective, and assumes participants invoke defences to reduce the effects of anxiety provoking 
thoughts and feelings about the work (Mills 2012; Ralph 2001; Rustin 2001; Schneider 2003). Research on the emotional experiences of South African child sexual abuse workers supplement the current literature, and contribute to knowledge of the psychological impact of therapeutic engagement with child sexual abuse in South Africa. This research also reports on useful measures that might enable individuals to continue child sexual abuse interventions.

\section{Method}

This study employed an explorative inductive research method, and followed a critical realist and contextual constructionist approach in an attempt to capture and describe some of the psychodynamics involved in child sexual abuse work (Burman 1997; Madill et al. 2000). Its multiple-case study design enabled the provision of "a broader array of evidence" and a more intense coverage of issues (Yin 2012, p. 131). Themes that emerged as participants reflected on their work were investigated, and the study's descriptive nature engages the reader with illustrated situations (Parker 2005). Critical realism admits to inherent subjectivity in producing knowledge, contending that the way we perceive truths depends on our beliefs and the social context in which these truths are observed. Contextual constructionism notes subjective meanings, and does not assume one true analysis that can only be revealed by using the "correct" methodology. Contextualism posits that knowledge is local, provisional, and situation dependent, and results vary according to the circumstances in which data are collected and analysed.

\section{Participants}

The participants in this study work for the only non-profit organisation that endeavours solely for the prevention and treatment of child sexual abuse in the greater Helderberg basin of the Western Cape. Given heavy case loads, multipleresponsibilities, and little staff, participants that work therapeutically with sexually abused children on a daily basis were included where their availability to be interviewed overlapped with the researcher's schedule. An unintentional result of this sampling process, namely that the four subsequently available participants from a multi-racial staff were female and White, lends a manner of homogeneity to the sample. Participants have postgraduate backgrounds in either social work or psychology. Although they did not intend to pursue a career in child sexual abuse work, they have a combined 32 years experience in the field (Table 1). At the time of interview, participants did not attend psychotherapy and supervision only intermittently so.

The relatively limited sample size directly reflects the small pool of possible respondents working therapeutically with sexually abused children in a large geographical area. Rapport could be developed with all four participants, and the intensity of their responses to interview questions counters the small sample size. A multiple-case study design enabled an in-depth exploration of some ways in which trauma work may have an emotional impact on child sexual abuse workers in 
Table 1 Participant demographic detail

\begin{tabular}{|c|c|c|c|c|c|c|}
\hline Participant & $\begin{array}{l}\text { Years experience } \\
\text { working with CSA }\end{array}$ & $\begin{array}{l}\text { Highest } \\
\text { qualification }\end{array}$ & Age & Gender & Race & $\begin{array}{l}\text { Enrolled in further } \\
\text { formal education }\end{array}$ \\
\hline 1 & 10 & MA (Social work) & 38 & Female & White & No \\
\hline 2 & 9 & $\begin{array}{l}\text { BA Honours } \\
\text { (Psvchologv) }\end{array}$ & 31 & Female & White & Yes \\
\hline 3 & 4 & $\begin{array}{l}\text { MA (Clinical } \\
\text { pastoral } \\
\text { counselling) }\end{array}$ & 27 & Female & White & No \\
\hline 4 & 9 & MA (Play therapy) & 37 & Female & White & Yes \\
\hline
\end{tabular}

low-income communities, and did not intentionally aim for representativeness of the sample. Although the data generated by participants' contributions outweighed the researcher's expectations, additional participants and interviews would serve to deepen and broaden findings of future studies. These might enjoy a larger and heterogeneous sample beyond the Helderberg and Western Cape, and explore child sexual abuse work whilst investigating the role that gender, race, resource allocation, and geographic location might play in the construction of South African work experiences.

\section{Data Collection and Validation}

Data were collected by means of semi-structured interviews with four participants, and seven interviews served as the means of data creation. Open-ended questions allowed for unexpected material to emerge and be explored. The interviews were recorded and transcribed with participants' permission. Interviews were conducted in Afrikaans and translated into English, and back translated to ensure their integrity. Notes made during and after interviews were kept securely as evidentiary data, and triangulated with audio-recordings and transcripts (Mello 2002).

Since "[w]e present ourselves...in terms of our stories or narratives", emerging themes were noted as interviews progressed, and object relations theory was used to consider defences that surfaced in participants' narratives (Levett 2002, p. 70). Specifically, data were examined by thematic analysis, and participants' narratives served as primary units of analysis (Babbie and Mouton 2007). The first round of interview material was explored to inform further reading, and enabled question design for second interviews. Themes shared by at least three participants were included, and exceptional illustrations of child sexual abuse work were included even if experienced by fewer participants. The results and discussion sections were combined due to the study's qualitative methodology.

Participant feedback was employed as a means of verifying findings. Participants were consulted on the accuracy of transcripts, and on the interpretive validity of research results (Babbie and Mouton 2007). They could volunteer additional information to confirm aspects of the data, or ask that interpretations not accurately reflective of their experiences be removed. 


\section{Ethical Considerations}

Participants were interviewed after providing written informed consent, and on condition that they could access a supervision or therapy environment should distressing material emerge during interview they may not have been consciously aware of (Agass 2002; Didhama et al. 2011; Etherington 2000; Motta 2012; Sommer 2008; Williams et al. 2012). They were offered the opportunity for feedback during the research process. Participants were not remunerated and are not personally identifiable in the research notes, transcriptions, or write-up. The research did not rely on any sources of funding.

\section{Results and Discussion}

\section{Experiences of Working with Child Sexual Abuse}

Literature on working with sexually abused children points to participating in the healing of another, the resilience of humanity, courage of the human spirit, and journeying with survivors (Brady et al. 1999; Brockhouse et al. 2011; Devilly et al. 2009; Herman 1997; Samios et al. 2012). Participants were able to reflect on emotional experiences by discussing their work during the interview process, and subsequent emerging themes are illustrated by referring to their verbatim accounts. Material emerged around themes of empathic engagement with child sexual abuse narratives, isolation, harassment of the work, system fatigue, and feelings of powerlessness and loss of idealism. Salient features of doing child sexual abuse work in South Africa also came to the fore.

From participant narratives, symptoms resembling vicarious traumatisation were described, and a psychoanalytic understanding thereof is posited. Considering these allowed participants to reflect on useful measures that support them in their daily interactions with child sexual abuse, namely internal resources, personal defences, and external sources of support.

\section{Empathic Engagement}

A child's projections offer important therapeutic material and, in turn, the management of therapist emotions is a significant treatment variable (Rock 1996). Projective identification could be useful therapeutically, but the child's and therapist's emotions could be lost to the therapeutic process if defensive blocking of traumatogenic projections is applied (Cunningham 1999; Mills 2012; Ralph 2001). Conversely, overidentification with child clients can be detrimental, resulting in negative coping, high stress levels, and negative countertransferences (Brockhouse et al. 2011; Collins and Long 2003; Reynolds-Mejia and Levitan 1990). Participants recognise this defendedness-openness continuum. At risk of empathic exhaustion, they disengage from their work at times in an effort to maintain a fine balance between engaging empathically and overidentifying with clients: "I need to stand 
with one foot in empathic connection, and the other in disconnection...get distance to think. Then I don't get overwhelmed" (Participant 3).

Physical illness as a result of sexual abuse makes it difficult for children, and for participants, to gain closure on the event. Cases where children contract a sexually transmitted illness or HIV are unbearable: "Syphilis injections hurt and children need three. After one, they don't come back. It hurts too much. There's nothing as unfair" (Participant 1). Where overwhelming feelings elicited by child sexual abuse realities can erode the ability to work effectively, it seems easier to rationalise the injustice of abuse: "It's probably their road" (Participant 1) (Coster and Schwebel 1997; McWilliams 1994).

\section{Isolation}

Participants explain that individuals outside the field can be quite defended against knowing about child sexual abuse-feeling contaminated by what they hear, they deny that such a thing can be true: "Their first reaction is usually: 'Children are prone to lying'. People don't want to hear any of this. It makes one feel lonely. If I want acknowledgment, I have to find friends with the same heart" (Participant 1). Unable to share thoughts and feelings about their work seems isolating. To experience validation, participants need to resonate with those who can bear witness and survive the knowledge.

At times participants shun their profession and avoid confronting others, perhaps themselves, with its realities. Some share experiences in supportive professional spaces, but spare these from the public. This highlights public versus private faces of participants as played out by the isolating nature of their work: "I just say I'm a teacher. It triggers a discussion...it's not a pleasant thing we work with. You have emotions that you can't share because they won't understand. That's what supervision is for" (Participant 2). Having become reticent to talk about work outside their field, participants protect others from their knowledge rather than confide in them: "I won't tell [my father] about my work, it would make him uncomfortable. It's hard to see how it affects others. We are involved in the battle. It's hectic for others" (Participant 3).

Underlying these narratives is the knowledge of things others can comfortably deny-paradoxical conditions in which participants can share their experiences with some but not with others. Discussions with colleagues in related fields enable a sharing of otherwise silencing knowledge. Censoring their feelings in public contributes to participants' experience of isolation. To find release from such loneliness, understanding spaces that can relieve them of their knowledge of child sexual abuse need to be accessed.

\section{Harassing Work}

Due to the unpredictability of child sexual abuse occurrences and emergencies, participants can not keep normal office hours. They must remain vigilant and contactable at any time on designated mobile phones that only communicate bad news: “The months I don't supervise crisis duty, my phone doesn't ring during the 
night...I can sleep without having to worry" (Participant 2). This constant watchfulness and lack of certainty in their working day complicates participants' opportunities for relaxation. Asserting time to themselves offers some respite:

"I decided not to do crisis duty, because I need the night to be mine" (Participant 3).

Days of completing paperwork literally and metaphorically alleviate the weight of case loads: "That helps lighten the load, all the other days...you don't get time for notes" (Participant 2). Apart from feeling productive, attending to documentation means doing the work without necessarily engaging with children's sexual abuse narratives.

\section{System Fatigue}

Participants seem exasperated by an unhelpful system that aggravates their already difficult work - one that fails to acknowledge the urgency with which child sexual abuse work needs to be expedited (Maier 2011): "The biggest frustration is the system, and there's nothing you can do...welfare, police, courts, jails, schools, parents who don't have insight" (Participant 2). Distressing and delayed court procedures further prolong the trauma (Killian and Brakarsh 2004): "Having to work with state organisations...everything gets postponed...the courts make us wait" (Participant 4). The navigability of proceedings can be influenced by professional politics, and (a lack of) status can hamper participants' ability to be helpful: "If you're not a psychiatrist...social workers and ordinary psychologists don't know anything. Counsellors know even less" (Participant 2). System fatigue best describes their feelings in this regard-holding the irony of having to work in, and simultaneously combat, the system on a daily basis.

The near impossibility of processing weighty case loads, of devoting the same amount of time to each case, can result in exhausting guilt feelings (Maier 2011): "I feel guilty about things I can't get to...but I do what I can" (Participant 1). The fatigue of trying to service existing clients as new cases flood in makes it difficult for participants to maintain sources of social support: "The danger is getting so busy because of huge case loads. You can't sacrifice your life for this job. I need to nurture [my] relationships" (Participant 3). An otherwise welcome pause from child sexual abuse work might be evaded lest imminent overwhelming exhaustion sets in: "I often feel bad and guilty...but there's no time to be depressed" (Participant 4) (McWilliams 1994).

\section{Powerlessness and Lost Idealism}

Participants seemingly suppress the overwhelming neediness that surrounds them. Sad and confused, they contain their own emotions in addition to the victims'. Feeling helpless against children's sexual abuse narratives, a resultant inability to think can be numbing (Haugaard 2000; Ralph 2001; Shevade et al. 2011): "One gets numb sooner or later to protect yourself" (Participant 2). Possibilities for comfort are created in distance from case details, and by concentrating on clients' personhoods: "Incest cases are the worst. I numb myself...look past that detail, and focus on the humanity and personhood of the child" (Participant 3). 
Participants see many children daily and compartmentalise in order to hold their own pain, that of the child, and the realities of sexual abuse (Brockhouse et al. 2011; McWilliams 1994). Their days slip away...nothing planned can be executed. They want to offer every client their best effort, but hurtle from one case to a next, stifling distress over one child to focus on another: "Some things are so urgent, you act immediately. You put the client's pain away, and you put your guilt away, because you can't help at that moment...nothing you planned can be dealt with. I think that's how one becomes screwed" (Participant 1). Unable to act on behalf of the children, subsequent feelings of inadequacy leave participants feeling powerless (Shevade et al. 2011): "I feel disempowered in cases where I can't do anything to help...incompetent" (Participant 3).

Participants have experienced effective and ineffective interventions, and resigned themselves to working within a hapless system. Although difficult to curb new child sexual abuse workers' optimism, a certain tension needs to be held between gaining experience in circumventing systemic obstacles, and preserving this idealism: "New workers have all kinds of plans. It's hard for me to say: 'That won't work, don't bother'. On the other hand, they must have their own experience of going through the system" (Participant 1).

Early idealism gradually makes way for comforting stories that offer relief from rescue fantasies - letting others find their own way, doing what one can (Malawista 2004; Michalopoulos and Aparicio 2012; Sommer 2008): "When I just started, I was ready for anything. But you pick your battles, not having to save everyone" (Participant 2). Given case loads, an obstructive system, and unpredictable days that require constant vigilance, participants have few spaces and little time in which to come to terms with the emotional effects of their work.

\section{Child Sexual Abuse Work in a Low-Income Context: Salient Features}

The research revealed some similarities in emotional experiences between the participating child sexual abuse workers and their counterparts as captured in the literature. Due to a working environment that includes a disobliging system coupled with socio-economic deprivation, salient features of child sexual abuse work in the Western Cape also emerged.

Court cases do not resolve efficiently in the Western Cape: "Here cases run for two, three, four years" (Participant 2). Due to an unresponsive system, participants feel they must do more, and contextualise child sexual abuse within a beleaguered society in need of earlier intervention: "[It] is actually part of a bigger messed up system. It's sad that children only get to us once there's sexual trauma" Participant 3).

Child sexual abuse has its own vernacular in the Western Cape. Language and contextual differences between clients and workers have led to misinterpretations: "Projection cards don't always work, because children can't identify with them. We learn the strangest words...many misunderstandings happen because of language" (Participant 2).

In low-income communities in the Western Cape, abuse is not children's only distressing experience: "Sexual abuse isn't just the abuse...it's poverty and 
violence. [Children] think it's bad because [the perpetrator] tore their clothes...or because their underwear was taken as evidence" (Participant 2). Child sexual abuse is but one traumatic experience that can introduce illness and HIV infection, negative emotional reactions to their disclosures, and lengthy court proceedings (Gibson 1996; Lovett 2004; Maseko 1998; Richter et al. 2004). Sexual abuse cannot be extricated from the lives of these children, cannot be separated from the trauma of pervasive poverty, deprivation, violence, hunger, and neglect: "Many children come back...revictimised. That's big here. The abuse is never ending " (Participant 2).

\section{Holding the Material: Psychological Impacts of Child Sexual Abuse Work}

Reynolds-Mejia and Levitan (1990) observed behavioural, somatic, and anxiety related symptoms in child sexual abuse workers attributable to unresolved introjected child sexual abuse material. Other authors note the influence such material might have on workers' worldview (Follette et al. 1994; Jankoski 2010; Jenkins and Baird 2002). Suggestions of such influences surfaced during the interview process.

Since working with sexually abused children can change participants' view of the world, others, and themselves, the literature recommends keeping track of such psychological effects (Cunningham 1999; Follette et al. 1994; Schauben and Frazier 1995; Shevade et al. 2011): “I don't look at [the town] like a tourist would. I question people's motives... This job has changed me, made me hard and impatient. I developed the ability to cut people away. That's something I couldn't do before” (Participant 1). Child sexual abuse can transform its workers into suspicious individuals, hardened by the limits of their interventions in a chaotic world: "This world is a messy place. I was nicer about people and things. It changes your whole life" (Participant 2).

The stress of the work might manifest in physical symptomology (McCann and Pearlman 1990): "I developed a stomach ulcer...my asthma is getting worse" (Participant 1). Such symptoms also allude to the work being perceived as persecutory: "I had a headache for three weeks. I even went for a brain scan, and there was nothing wrong. And I'm hypervigilant...from hearing these [child sexual abuse] things all day" (Participant 2).

At times, participants experience child sexual abuse material as anxiety provoking, dynamic dream material or exhausting intrusive thoughts (Bezuidenhout et al. 2005): "I think about [work] before I go to sleep, when I wake up, in the bath. I had a nightmare about someone trying to attack us...rape somebody and kill her. That's where [the work] sits" (Participant 3). The material lingers: "You can't get it out of your head. This stuff gets stuck and influences your life" (Participant 2). As a metaphor for the isolating nature of child sexual abuse work, one participant is alone when anxiety symptoms are triggered by medico-legal emergencies: "The hospital traumatised me. I develop a cold sweat and nausea when I have to go there...I just want to get out. That smell... [it] really damaged me" (Participant 1).

By reorganising furniture in a renewal ritual that enables her work to continue, a participant enacts feelings of anger: "I wipe everything off a table ...then I pick it up 
again. I rearrange my office. Then I can carry on" (Participant 2). Having been on leave from her working environment, another seemed unprepared for engaging the necessary defences with which to confront child sexual abuse work (Mills 2012): "My defences were down. I often get annoyed with unhelpful people, but never that furious. I almost blacked out. I didn't realise how angry [child sexual abuse] makes me. You are either ready and hard for this work, or you're not" (Participant 1).

\section{A Psychoanalytic Understanding of Vicarious Traumatisation}

The theme of vicarious traumatisation emerged as data accumulated. Prior to exploring a psychoanalytic understanding, a more traditional definition is offered alongside those of child sexual abuse presented earlier in the discussion.

Introduced by McCann and Pearlman (1990), vicarious traumatisation describes one kind of transformation therapists may undergo due to empathic engagement with clients' trauma material resulting in negative coping, high stress levels, and negative countertransferences (Ahmadi et al. 2011; Brady et al. 1999; Culver Jankoski 2010; Culver et al. 2011; Collins and Long 2003; Jenkins and Baird 2002). A more psychoanalytic understanding of vicarious traumatisation can be put forward in keeping with the earlier description of child sexual abuse as

... a piece of madness is forced into [the child] so that the child can no longer make sense of his experiences, thoughts and feelings. [T]he same process can happen to those working with the child (Ralph 2001, p. 286).

Following this interpretation, such "madness" can be transferred into child sexual abuse workers, leaving them vulnerable to traumatogenic introjections (Brady et al. 1999; Collins and Long 2003). "Mad" projections can trigger negative countertransference experiences in workers, who may defensively resist introjecting traumatogenic narratives (Hafkenscheid 2005; Mills 2012; Ralph 2001; Shevade et al. 2011). This blocking can lead to defensive enactments of intolerable emotions-by means of reaction formation, for example, anger and helplessness might manifest as compassion and concern, or grief and shock as anger and rage (McElroy and McElroy 1991; McWilliams 1994; Shevade et al. 2011). By processing negative countertransferences, exploring their potential emotional range, and maintaining awareness of dispositions toward splitting, workers could circumvent vicarious traumatisation due to prolonged engagement with potent child sexual abuse narratives (Ahmadi et al. 2011; Culver et al. 2011; Schneider 2003).

\section{Continuing Child Sexual Abuse Interventions: Useful Measures}

\section{Internal Resources}

Participants identified personal characteristics that support them in their work with sexually abused children. One participant's minimising defence and ability to contain her emotional responses contribute to composure under pressure (Clarke 2011; Rustin 2001; Samios et al. 2012): "I can stay calm and sort things out. I 
minimise so I can handle it for now" (Participant 1). Another recommends having some "...healthy suspicion. And ways of unloading" (Participant 3). Additional traits that reportedly assist participants in their work include self knowledge, assertiveness, persistence, commitment, kindness, and compassion. Contempt and compassion for the context of child sexual abuse might mirror one participant's defensive splitting (Clarke 2011; McWilliams 1994): "I have compassion but am very judgemental. I can deal with grey areas, but I'm not fond of them. Wrong is wrong and right is right. I'm black and white" (Participant 4).

Participants acknowledge that "self awareness is very important" (Participant 3 ), and in light of the therapeutic use of projective identification, recognise the need to differentiate their countertransferences from clients' projections (Brockhouse et al. 2011; Rosenberger and Hayes 2002; Shevade et al. 2011; Stone 2006): "One has to distinguish between one's own and the client's stuff" (Participant 1).

Rustin (2001) suggests that child sexual abuse workers remain open to self examination and realistic about their limits, and participants concur: "Self awareness is important for self preservation. Be realistic, know your limits" (Participant 2). Retiring from child sexual abuse work is a personal and professional choice that also requires self awareness. One participant draws the line at no longer being able to reconcile her clients' needs with her resources to address these (Samios et al. 2012): “When you've heard absolutely everything and you start rushing clients. If you become desensitised, it's time to move on" (Participant 1). Another will exit the field when the longing for a life free from child sexual abuse material coincides with compassion burnout (Devilly et al. 2009): "The day I don't get upset over a case I'll leave. One wishes sometimes to have a normal life" (Participant 2).

Self care, stress reduction, "[r]est, relaxation, physical exercise...[and] vacations" are vital for both personal and professional functioning (Coster and Schwebel 1997, p. 11; see also Culver et al. 2011; Williams et al. 2012): "You have to look after yourself" (Participant 2). Participants seek uplifting spaces for some reprieve from the heaviness of child sexual abuse material: "Nature helps. Exercise, sleeping, eating, being social...one has to find some lightness" (Participant 3). They attempt to expand their lives outside of a work environment in which they can get easily trapped: "I want to be more balanced and do things I enjoy. Otherwise I get stuck" (Participant 1).

By upholding self awareness and care, participants remain capable of gauging their ability to work effectively. Asserting professional and personal boundaries further conserves their capacity for their work: "You must have boundaries. People have the ability to steal your energy" (Participant 4). One Helderberg town's relatively small size, coupled with the sheer number of child sexual abuse cases, contributes to involuntary confrontations with the work. Previously unable to assert boundaries, one participant felt obliged to have sessions with clients that spot her in public: "You see your clients everywhere. It took me five years to say: 'I can't talk now, phone for an appointment', without feeling guilty" (Participant 2). 


\section{Personal Defences}

Collins and Long (2003) posit that child sexual abuse workers defend against the narratives they bear witness to: "I think one [defends] to survive. Like, maybe there's some good in it...otherwise I won't get through it" (Participant 1). Participants encourage themselves that their work is not hopeless: "Hope definitely plays a big role...I wouldn't have done without it" (Participant 3). Splitting hopelessness off, work and home are safely shielded from infringing on one another (McWilliams, 1994): "It's not that hopeless. You purposefully cut it off. Friday you go home, and forget about work" (Participant 2).

One participant is conscious about defending against the work. In doing so, displaced grief might surface when confronted with something she wants for herself, or wishes someone might facilitate, take over, on her behalf (McWilliams 1994; Mills 2012): "I think I use denial and suppression. I'll be watching 'Oprah' or a makeover show, then I'll sit and cry about that. I don't really cry about things I should" (Participant 1).

She wonders whether she employs projective identification as a drive in her work...helping others but unable to ask for this herself. Expelling the part of her that needs help, she projects into the children and recognises their need-ultimately addressing hers by helping (McWilliams 1994). Unconscious guilt about this might invoke reparative anxiety, in which repair of the client relationship addresses a need to restore a relationship with an own internalised object (Mancillas 2006; Waska 2007). The participant identifies this process in the adolescents she helps: "When they come to terms with what happened to them, they also want to help others one day...maybe they feel if they do that, what happened to them will make sense" (Participant 1).

Intolerable material is rationalised into a more palatable account: "Two boys sodomised a dog. But they were young, it was more a function of something else, maybe FAS [Foetal Alcohol Syndrome]. They were very delayed" (Participant 3). Similarly, effecting "small" pieces of child sexual abuse work fends off the hopelessness of circumstance: "There is nowhere for these children to stay...you can't change those things. So you have to do this small little bit of work" (Participant 2).

One participant describes her busy schedule: "I work at six hundred different places, I'm never at home. I have lots of stuff going on at the same time. It keeps me going. I bead at night, or mark student files. I like being busy" (Participant 4). Not dispelling healthy variant activities, these might be likened to a manic defence against thoughts and experiences of her work since her "[a]cting out occurs mainly in the form of flight" (McWilliams 1994, p. 249).

For another, the work causes hopelessness and grief, but by reaction formation is enacted by unjustified anger and rage (McElroy and McElroy 1991; McWilliams 1994): "I can carry on like a banshee-people think I've completely lost it" (Participant 2).

Participants devote their lives to reli(e)ving sexually abused children's distress: "You want to make a difference...because you have this vision of a better life" (Participant 2). Perhaps their own need to be helped is addressed in this way. 
Helping these children becomes an object of great focus, concern, and control indeed (Waska 2007).

\section{External Sources of Support}

Ralph (2001) explains that "[h]aving a space to think about the processes and mechanisms that are enacted when working with [sexually abused] children is crucial" (p. 287). Supervision and personal therapy play an essential role in helping participants make sense of their work (Didhama et al. 2011; Goddard and Hunt 2011; Motta 2012; Samios et al. 2012; Sommer 2008; Williams et al. 2012): "I don't think one can do this work without supervision. You'll burn out. I also made an appointment with a psychologist" (Participant 2). Supervision and therapy offer neutral spaces in which participants can come to terms with the force of their work: “[People] won't understand. That's what supervision is for" (Participant 2).

The literature suggests that a supportive, physically secure, and respectful work environment can ameliorate the stress of child sexual abuse work (Bonach and Heckert 2012; Brady et al. 1999; Brockhouse et al. 2011; Choi 2011; Coster and Schwebel 1997; Williams et al. 2012). Participants corroborate this: "My work environment must feel safe. I absolutely need to be able to rely on colleagues" (Participant 2). The work environment impacts on participants' capacity to cope with cases, and their narratives reflect a need for a constructive work environment in which they feel contained: "I definitely wouldn't have been able to do this on my own. I can't work if there's stress in the office. We're united in our purpose...that should be enough for people to get along" (Participant 3).

Participants emphasise further professional development as essential, and do not feel that formal training prepared them for child sexual abuse work necessarily (Sommer 2008): "Training helps, but a lot of the work is adaption. When you go on a course, you see things can be done differently" (Participant 2). Formal education might have provided an experiential foundation, but continuous professional development is deemed invaluable: "Training contributed to shaping me and my way of thinking. But professional development always plays a role" (Participant 3 ).

Peer and social support are protective factors when intervening therapeutically with sexually abused children and participants do not take this for granted (Coster and Schwebel 1997; Hall 2009; Michalopoulos and Aparicio 2012): "My support network is important. I don't want friends and family to feel that, because I work with hectic things, they can't tell me how they're doing" (Participant 3). The significance of social support is further underscored: "My whole family is there to help if need be" (Participant 4).

During the interview process, participants were able to consider the emotional effects of prolonged therapeutic contact in child sexual abuse work. Subsequently, material emerged around themes of empathic engagement with child sexual abuse narratives, isolation, harassment of the work, system fatigue, and feelings of powerlessness and loss of idealism. Salient features of doing child sexual abuse work in South Africa also came to the fore. Participants described symptoms similar to vicarious traumatisation, and a psychoanalytic understanding thereof was 
introduced. Reflecting on these enabled participants to share useful measures that support them in their daily interactions with child sexual abuse.

\section{Future Research}

Individuals have unique subjectivities that contribute to distinctive transferencecountertransference dimensions within dyads. Intersubjective research can explore countertransference as a co-created phenomenon by child sexual abuse worker and client, when creating research data with child sexual abuse workers, and in supervision with child sexual abuse workers (Goddard and Hunt 2011; Rasmussen 2005; Southern 2007). Projective identification can then be conceptualised not only as a defence mechanism, but a means of communication between subjectivities (Waska 2007). In this way, the effect that socio-political issues of race, class, and gender have on the child sexual abuse working environment can be taken forward in future studies of child sexual abuse in South African communities (Chapman 2006).

\section{Conclusion}

This study attempted to understand the emotional effects of prolonged and daily therapeutic engagement with sexually abused children in low-income Western Cape communities. Material emerged around themes of empathic engagement with child sexual abuse narratives, isolation, harassment of the work, system fatigue, and feelings of powerlessness and loss of idealism.

Salient features of working with sexually abused children in a low-income South African context surfaced that can expand the current literature. These consist of large case loads that fuel guilt and exhaustion as new cases stream in; language barriers, miscommunications, and misunderstandings between workers and clients; a futile system coupled with pervasive socio-economic deprivation and neglect; and client narratives telling of multiple traumas of child sexual abuse, hunger, abandonment, poverty and violence that make it difficult to extricate child sexual abuse experiences from clients' lives.

During the course of the study, child sexual abuse work materialised as a rewarding experience that can demand sacrifice-an unvarying battle against perpetrators, indifference, poverty, and illness. Participants use defences and comforting stories to endure the daily onslaught of traumatogenic material. They take what little solace effective interventions offer, and resist both compassionate and system fatigue - the struggle to do good work in an unworkable system.

Participants described symptoms similar to vicarious traumatisation, and a psychoanalytic understanding thereof was posited. Reflecting on these enabled participants to share useful measures that support them in their interactions with sexually abused children, namely internal resources, personal defences, and external sources of support.

In daily battles with child sexual abuse in the Western Cape, workers attempt to survive the force of children's abuse and neglect narratives; influence the system 
that must be used; and tolerate mental pain when dealing with intolerable trauma material. To enable continued effective therapeutic engagement, child sexual abuse workers should have access to opportunities to acknowledge and process dynamic material defended against during the course of their work.

Acknowledgments The authors thank the child sexual abuse workers who agreed to participate in this study, for the opportunity they afforded us to attempt an understanding of their world. The reviewers are thanked for helpful suggestions.

\section{References}

Agass, D. (2002). Countertransference, supervision and the reflection process. Journal of Social Work Practice, 16, 125-133.

Ahmadi, K., Azampoor-Afshar, S., Karami, G., \& Mokhtari, A. (2011). The association of veterans' PTSD with secondary trauma stress among veterans' spouses. Journal of Aggression, Maltreatment and Trauma, 20, 636-644.

Babbie, E., \& Mouton, J. (2007). The practice of social research. Cape Town: Oxford University Press.

Bezuidenhout, M., Desai, A., \& Lubbe, T. (2005). Coping with mental and physical violence in the playroom. Psycho-Analytic Psychotherapy in South Africa, 13, 43-62.

Bonach, K., \& Heckert, A. (2012). Predictors of secondary traumatic stress among children's advocacy center forensic interviewers. Journal of Child Sexual Abuse, 21, 295-314.

Brady, J. L., Guy, J. D., Poelstra, P. L., \& Brokaw, B. F. (1999). Vicarious traumatisation, spirituality, and the treatment of sexual abuse survivors: A national survey of women psychotherapists. Professional Psychology: Research and Practice, 30, 386-393.

Brockhouse, R., Msetfi, R. M., Cohen, K., \& Joseph, S. (2011). Vicarious exposure to trauma and growth in therapists: The moderating effects of sense of coherence, organizational support, and empathy. Journal of Traumatic Stress, 24, 735-742.

Burman, E. (1997). Minding the gap: Positivism, psychology, and the politics of qualitative methods. Journal of Social Issues, 4, 785-801.

Chapman, R. T. (2006). Internalised racism of the clinician and the treatment dynamic. Journal of Emotional Abuse, 6, 219-228.

Choi, G. Y. (2011). Organizational impacts on the secondary traumatic stress of social workers assisting family violence or sexual assault survivors. Administration in Social Work, 35, 225-242.

Clarke, J. (2011). Working with sex offenders: Best practice in enhancing practitioner resilience. Journal of Sexual Aggression, 17, 335-355.

Clarkson, P., \& Nuttall, J. (2000). Working with countertransference. Psychodynamic Counselling, 6, 360-378.

Collins, S., \& Long, A. (2003). Working with the psychological effects of trauma: Consequences for mental healthcare-workers - a literature review. Journal of Psychiatric and Mental Health Nursing, $10,417-424$.

Coster, J. S., \& Schwebel, M. (1997). Well-functioning in professional psychologists. Professional Psychology, Research and Practice, 28, 5-13.

Culver, L. M., McKinney, B. L., \& Paradise, L. V. (2011). Mental health professionals' experiences of vicarious traumatization in post-hurricane Katrina New Orleans. Journal of Loss and Trauma, 16, $33-42$.

Cunningham, M. (1999). The impact of sexual abuse treatment on the social work clinician. Child and Adolescent Social Work Journal, 16, 277-290.

Dawes, A., Richter, L., \& Higson-Smith, C. (2004). Confronting the problem. In L. Richter, A. Dawes, \& C. Higson-Smith (Eds.), Sexual abuse of young children in southern Africa (pp. 1-18). Cape Town: HSRC Press.

Devilly, G. J., Wright, R., \& Varker, T. (2009). Vicarious trauma, secondary traumatic stress or simply burnout? Effect of trauma therapy on mental health professionals. The Australian and New Zealand Journal of Psychiatry, 2009(43), 373-385.

Didhama, S., Dromgolea, L., Csiernikb, R., Karleyb, M. L., \& Hurley, D. (2011). Trauma exposure and the social work practicum. Journal of Teaching in Social Work, 31, 523-537. 
Etherington, K. (2000). Supervising counsellors who work with survivors of childhood sexual abuse. Counselling Psychology Quarterly, 13, 377-389.

Follette, V. M., Polusny, M. M., \& Milbeck, K. (1994). Mental health and law enforcement professionals: Trauma history, psychological symptoms, and impact of providing services to child sexual abuse survivors. Professional Psychology: Research and Practice, 25, 275-282.

Gabbard, G. O. (2001). A contemporary psychoanalytic model of countertransference. Psychotherapy in Practice, 57, 983-991.

Gibson, K. (1996). Working with children in violence: The therapeutic classroom. Psycho-analytic Psychotherapy in South Africa, 4, 19-31.

Goddard, C., \& Hunt, S. (2011). The complexities of caring for child protection workers: The contexts of practice and supervision. Journal of Social Work Practice, 25, 413-432.

Hafkenscheid, A. (2005). Event countertransference and vicarious traumatisation: Theoretically valid and clinically useful concepts? European Journal of Psychotherapy, Counselling, and Health, 7, 159-168.

Hall, J. C. (2009). Utilizing social support to conserve the fighting strength: Important considerations for military social workers. Smith College Studies in Social Work, 79, 335-343.

Haugaard, J. J. (2000). The challenge of defining child sexual abuse. American Psychologist, 55, 1036-1039.

Herman, J. (1997). Trauma and recovery: The aftermath of violence-from domestic abuse to political terror. New York: Basic Books.

Jankoski, J. (2010). Is vicarious trauma the culprit? A study of child welfare professionals. Child welfare, 89, 105-120.

Jenkins, S. R., \& Baird, S. (2002). Secondary traumatic stress and vicarious trauma: A validational study. Journal of Traumatic Stress, 5, 423-432.

Johnson, C. F. (2004). Child sexual abuse. Lancet, 364, 462-470.

Killian, B., \& Brakarsh, J. (2004). Therapeutic approaches to sexually abused children. In L. Richter, A. Dawes, \& C. Higson-Smith (Eds.), Sexual abuse of young children in southern Africa (pp. 367-394). Cape Town: HSRC Press.

Klein, M. (1975). The psycho-analysis of children. In A. Strachey \& H. A. Thorner (Eds.). London: Virago Press.

Levett, A. (2002). Problems of cultural imperialism in the study of child sexual abuse. In P. Reavy \& S. Warner (Eds.), New feminist stories of child sexual abuse: Sexual scripts and dangerous dialogue. New York: Routledge.

Lovett, B. B. (2004). Child sexual abuse disclosure: Maternal response and other variables impacting the victim. Child and Adolescent Social Work Journal, 21, 355-371.

Madill, A., Jordan, A., \& Shirley, C. (2000). Objectivity and reliability in qualitative analysis: Realist, contextualist and radical constructionist epistemologies. British Journal of Psychology, 91, 1-20.

Maier, S. L. (2011). Rape crisis centers and programs: "Doing amazing, wonderful things on peanuts". Women and Criminal Justice, 21, 141-169.

Malawista, K. L. (2004). Rescue fantasies in child therapy: Countertransference/transference enactments. Child and Adolescent Social Work Journal, 21, 373-386.

Mancillas, A. (2006). Recognising and utilising projective identification in brief psychodynamic therapy: A case example. Clinical Social Work Journal, 34, 267-278.

Maseko, M. (1998). Work with abused children in Katlehong. Psycho-analytic Psychotherapy in South Africa, 6, 2-11.

McCann, I. L., \& Pearlman, L. A. (1990). Vicarious traumatisation: A framework for understanding the psychological effects of working with victims. Journal of Traumatic Stress, 3, 131-149.

McElroy, L. P., \& McElroy, R. A. (1991). Countertransference issues in the treatment of incest families. Psychotherapy, 28, 48-54.

McWilliams, N. (1994). Psychoanalytic diagnosis: Understanding personality structure in the clinical process. New York: The Guilford Press.

Mello, R. A. (2002). Collocation analysis: A method for conceptualising and understanding narrative data. Qualitative Research, 2, 231-243.

Michalopoulos, L. M., \& Aparicio, E. (2012). Vicarious trauma in social workers: The role of trauma history, social support, and years of experience. Journal of Aggression, Maltreatment and Trauma, 21, 646-664. 
Mills, S. M. (2012). Unconscious sequences in child protection work: Case studies of professionals' experiences of child removal. Journal of Social Work Practice: Psychotherapeutic Approaches in Health, Welfare and the Community, 26, 301-313.

Mitchell, S. A., \& Black, M. J. (1995). Freud and beyond: A history of modern psychoanalytic thought. New York: Basic Books.

Motta, R. W. (2012). Secondary trauma in children and school personnel. Journal of Applied School Psychology, 28, 256-269.

Parker, I. (2005). Qualitative psychology: Introducing radical research. Berkshire: Open University Press.

Potgieter, R. (2000). The internal trauma of the sexually abused child. Child Abuse Research in South Africa, 1, 33-39.

Ralph, I. (2001). Countertransference, enactment and sexual abuse. Journal of Child Psychotherapy, 27, $285-301$.

Rasmussen, B. (2005). An intersubjective perspective on vicarious trauma and its impact on the clinical process. Journal of Social Work Practice, 19, 19-30.

Reynolds-Mejia, P., \& Levitan, S. (1990). Countertransference issues in the in-home treatment of child sexual abuse. Child Welfare, 39, 53-61.

Richter, L., Dawes, A., \& Higson-Smith, C. (Eds.). (2004). Sexual abuse of young children in southern Africa. Cape Town: HSRC Press.

Rock, B. (1996). Betwixt and between? The role of emotion in the care of severely traumatised children. Psycho-analytic Psychotherapy in South Africa, 4, 72-85.

Rosenberger, E. W., \& Hayes, J. A. (2002). Origins, consequences, and management of countertransference: A case study. Journal of Counseling Psychology, 49, 221-232.

Russell, D. E. H. (1986). The incest legacy. Sciences, 26, 28-32.

Rustin, M. (2001). The therapist with her back against the wall. Journal of Child Psychotherapy, 27, 273-284.

Samios, C., Rodzik, A. K., \& Abel, L. M. (2012). Secondary traumatic stress and adjustment in therapists who work with sexual violence survivors: The moderating role of posttraumatic growth. British Journal of Guidance and Counselling, 40, 341-356.

Schauben, L. J., \& Frazier, P. A. (1995). Vicarious trauma: The effects on female counselors of working with sexual violence survivors. Psychology of Women Quarterly, 19, 49-64.

Schneider, J. A. (2003). Working with pathological and healthy forms of splitting: A case study. Bulletin of the Menninger Clinic, 67, 32-49.

Shevade, D., Norris, E., \& Swann, R. (2011). An exploration of therapists' reactions to working with children displaying sexually problematic behaviour: A thematic analytic study. Journal of Child Psychotherapy, 37, 52-74.

Sommer, C. A. (2008). Vicarious traumatization, trauma-sensitive supervision, and counselor preparation. Counselor Education and Supervision, 48, 61-72.

Southern, S. (2007). Countertransference and intersubjectivity: Golden opportunities in clinical supervision. Sexual Addiction and Compulsivity, 14, 279-302.

St. Clair, M. (1996). Object relations and self psychology: An introduction. Pacific Grove: Brooks/Cole Publishing Company.

Stone, M. (2006). The analyst's body as tuning fork: Embodied resonance in countertransference. Journal of Analytical Psychology, 51, 109-124.

Swartz, L. (2002). Culture and mental health: A southern African view. Cape Town: Oxford University Press.

Waska, R. (2007). Projective identification as an inescapable aspect of the therapeutic relationship. Psychoanalytic Social Work, 14, 43-64.

Way, I., Van Deusen, K. M., Martin, G., Applegate, B., \& Jandle, D. (2004). Vicarious trauma: A comparison of clinicians who treat survivors of sexual abuse and sexual offenders. Journal of Interpersonal Violence, 19, 49-71.

Williams, A. M., Helm, H. M., \& Clemens, E. V. (2012). The effect of childhood trauma, personal wellness, supervisory working alliance, and organizational factors on vicarious traumatization. Journal of Mental Health Counseling, 34, 133-154.

Yin, R. K. (2012). Applications of case study research. Los Angeles: Sage. 